\title{
DESKRIPSI INTENSITAS SUARA DI RUANG RAWAT INAP RS PKU MUHAMMADIYAH GOMBONG KABUPATEN KEBUMEN TAHUN 2017
}

\author{
Firani Uji Novia ${ }^{1)}$, Yulianto ${ }^{2)}$ \\ Jurusan Kesehatan Lingkungan, Politeknik Kesehatan Kemenkes Semarang, \\ Jl.Raya Baturaden KM 12 Purwokerto, Indonesia
}

\begin{abstract}
Abstrak
Keputusan Menteri Kesehatan Republik Indonesia Nomor 1204/MENKES/SK/X/2004 tentang Persyaratan Kesehatan Lingkungan Rumah Sakit menjelaskan mengenai intensitas suara di ruang perawatan yang akan mengakibatkan gangguan apabila melebihi NAB yaitu 40 - 45 dB. Berdasarkan masalah tersebut, peneliti ingin mengetahui deskripsi intensitas suara di ruang rawat inap RS PKU Muhammadiyah Gombong tahun 2017.Metode yang digunakan adalah observasional dengan analisis deskriptif yang bertujuan untuk mengevaluasi intensitas suara di ruang rawat inap Rumah Sakit PKU Muhammadiyah Gombong tahun 2017. Hasil yang didapatkan dari pengukuran intensitas suara yang dilakukan pada 5 bangsal yaitu Inayah, Barokah, Husna, Salma, dan Hidayah selama pengukuran 24 jam yaitu terendah yaitu 42,69 dB pada lokasi Ruang Salma titik 3 Leq 2 dan intensitas suara tertinggi yaitu 76,25 dB pada lokasi Ruang Husna titik 4 Leq 1. Hasil pengukuran intensitas suara menurut jam pengukuran perkelasnya di RS PKU Muhammadiyah Gombong tahun 2017 diperoleh hasil rata - rata intensitas suara terendah yaitu 46,47 dB pada jam pengukuran 04.00 WIB Kelas Utama dan rata - rata intensitas suara tertinggi yaitu 67,90 dB pada jam pengukuran 20.00 WIB Kelas Jamkesmas. Berdasarkan hasil tersebut dapat disimpulkan bahwa sebagian besar hasil pengukuran intensitas suara di ruang rawat inap RS PKU Muhammadiyah Gombong tahun 2017 melebihi NAB. Saran peneliti agar dilakukan pemantauan secara berkala serta pemasangan peringatan agar tidak membuat gaduh.
\end{abstract}

Kata kunci: Rumah sakit; Intensitas suara; Kesehatan Lingkungan

\begin{abstract}
The description of the sound intensity in inpatient wards at PKU Muhammadiyah Gombong hospital Kebumen Regency in 2017. Decree of the Minister of Health of the Republic of Indonesia No. 1204/MENKES/SK/X/2004 on Hospital Environmental Health Requirements describes the sound intensity in the treatment room which will cause disturbance if it exceeds the NAB of $40-45 \mathrm{~dB}$. Based on that problem, the researcher is curious to know about The Description of The Sound Intensity in Inpatient Wards at PKU Muhammadiyah Gombong Hospital, Kabupaten Kebumen in 2017. The method used is observasional with descriptive analysis that aims to evaluate the sound intensity in inpatient wards at PKU Muhammadiyah Gombong Hospital in 2017. The results obtained from the measurement of the sound intensity conducted on 5 wards are Inayah, Barokah, Husna, Salma, and Hidayah. During 24 hours measurement, the lowest sound intensity is $42.69 \mathrm{~dB}$ at Salma, point 3 Leq 2 and the highest sound intensity is 76.25 DB at Husna, point 4 Leq 1. According to time measurement per its class in PKU Muhammadiyah Gombong Hospital in 2017, it is obtained that the lowest average of sound intensity is 46,47 dB at 04.00 a.m in Main Class and that the highest average of sound intensity is $67.90 \mathrm{~dB}$ at 20.00 p.m in Jamkesmas Class. Based on the result, it can be concluded that most of the result of sound intensity measurement in inpatient wards at PKU Muhammadiyah Gombong Hospital in 2017 exceeds NAB. The researcher recommends to periodically monitor and to install and set up the Noise Warning Sign
\end{abstract}

Keywords: hospital; sound intensity; environmenthal health 


\section{Pendahuluan}

Upaya kesehatan lingkungan ditujukan untuk mewujudkan kualitas lingkungan yang sehat, baik fisik, kimia, biologi, maupun sosial yang memungkinkan setiap orang mencapai derajat kesehatan yang setinggitingginya. Lingkungan sehat mencakup lingkungan permukiman, tempat kerja, tempat rekreasi, serta tempat dan fasilitas umum harus bebas dari unsur-unsur yang menimbulkan gangguan kesehatan, antara lain: limbah cair, limbah padat, limbah gas, sampah yang tidak diproses sesuai dengan persyaratan yang ditetapkan pemerintah, binatang pembawa penyakit, zat kimia yang berbahaya, kebisingan yang melebihi ambang batas, radiasi sinar pengion dan non pengion, air yang tercemar, udara yang tercemar, dan makanan yang terkontaminasi. Guna mewujudkan derajat kesehatan yang setinggi-tingginya bagi masyarakat, diselenggarakan upaya kesehatan yang terpadu dan menyeluruh dalam bentuk upaya kesehatan perseorangan dan upaya kesehatan masyarakat. Upaya kesehatan diselenggarakan dalam bentuk kegiatan dengan pendekatan promotif, preventif, kuratif, dan rehabilitatif yang dilaksanakan secara terpadu, menyeluruh, dan berkesinambungan ( UU no. 36 tahun 2009 tentang kesehatan pasal 162-163 dan pasal 46-47).

Keputusan Menteri Kesehatan nomor 1204 tahun 2004 tentang persyaratan kesehatan lingkungan Rumah Sakit menjelaskan bahwa Rumah Sakit sebagai sarana pelayanan kesehatan, tempat berkumpulnya orang sakit maupun orang sehat, atau dapat menjadi tempat penularan penyakit serta memungkinkan terjadinya pencemaran lingkungan dan gangguan kesehatan, untuk menghindari gangguan kesehatan tersebut maka perlu penyelenggaraan kesehatan lingkungan rumah sakit sesuai dengan persyaratan kesehatan. Dalam kesehatan kerja, bising diartikan sebagai suara yang dapat menurunkan pendengaran baik secara kuantitatif (peningkatan ambang pendengaran) maupun kualitatif (penyempitan spectrum pendengaran), berkaitan dengan faktor intensitas, frekuensi, durasi dan pola waktu (Pedoman Teknis Upaya Kesehatan Kerja Di Rumah Sakit, 2001 hal 63).

Pajanan terhadap intensitas suara yang tinggi dapat menimbulkan dampak negatif baik bersifat audotorial maupun non auditorial. Dampak kesehatan yang bersifat non auditorial antara lain mengganggu komunikasi ,gangguan tidur, gangguan perilaku, gangguan fisiologis antara lain ditandai dengan sakit kepala, mual, berdebar yang bersifat auditorial dikenal sebagai "occupational hearing loss", termasuk trauma akustik dan Noise Induce Hearing Loss (NIHL) (Pedoman Teknis Upaya Kesehatan Kerja Di Rumah Sakit, 2001 h. 64).

\footnotetext{
${ }^{1)}$ E-mail: firaniujin@gmail.com

2)E-mail: yulianto_61@yahoo.com
}

Selvina Levina Ukru (Manado,2016) menyatakan bahwa telah dilakukan penelitian untuk mengukur dan menganalisis tingkat intensitas suara yang ada di lingkungan Rumah Sakit Siloam Jalan Sam Ratulangi Manado. Pengambilan data dilakukan dengan menggunakan Sound Level Meter DB 200 pada dua lokasi pengukuran (5 titik). Data yang diperoleh adalah nilai tingkat intensitas kebisingan pada masing-masing titik pengukuran. Hasil analisis menunjukkan bahwa tingkat kebisingan tertinggi di lokasi 1 yaitu $74,5 \mathrm{~dB}$ dan 59,01 dB untuk lokasi 2. Hasil ini menunjukkan Rumah Sakit Siloam Manado memiliki tingkat kebisingan yang melebihi batas kebisingan yang diperkenankan di Rumah Sakit yaitu sebesar 55 dB Menurut Keputusan Menteri Negara Lingkungan Hidup No. 48 Tahun 1996.

Rumah Sakit PKU Muhammadiyah Gombong adalah Rumah Sakit Swasta Madya yang memberikan pelayanan medis 24 jam meliputi layanan Rawat Inap, Rawat Jalan, ICU, Hemodialisa ,IGD, poly, IBS, Fasilitas Pelayanan Umum ( Masjid dan ATM), Pemulasan Jenasah, Home care, Ambulan Gawat Darurat dan telah melakukan MoU Pelayanan dengan pihak kesehatan yaitu : PT Askes, Jamkesmas, Jamsostek, Jasa Raharja, Asuransi Tafakul, DSM,PT KAI, Allianz, PLN dan Telkom. Berdasarkan pengukuran intensitas suara yang dilakukan oleh pihak Pengelola Lingkungan di Rumah Sakit PKU Muhammadiyah Gombong pada Bulan Agustus 2016 didapatkan hasil pada Ruang Perawatan Salma adalah 60,3 dBA dengan NAB 45 dBA, Instalasi Gizi adalah 77,9 dBA dengan standar $78 \mathrm{dBA}$, dan pada ruang ICU adalah 58,1 dBA dengan standar $40 \mathrm{dBA}$ yang artinya intensitas suara pada Ruang Perawatan Salma dan ICU belum memenuhi persyaratan sedangkan pada Instalasi Gizi sudah memenuhi persyaratan (laporan pengukuran cuaca kerja RS PKU Muhammadiyah Gombong, Agustus 2016).

Ruang rawat inap di RS PKU Muhammadiyah merupakan tempat yang berpotensi menimbulkan gangguan intensitas suara diantaranya berasal dari aktivitas perawat seperti perawat jaga berbicara terlalu keras, dokter,pasien, mesin-mesin medis, penunggu pasien seperti setiap pasien ditunggu oleh keluarga lebih dari 1 orang, pengunjung/penjenguk seperti banyaknya pembesuk yang berkunjung ke ruang perawatan pasien sebelum waktu jam kunjung RS maupun yang berasal dari lingkungan luar rumah sakit seperti jalan raya yang menghasilkan jenis bising yang berbeda. Ruang rawat inap di RS PKU Muhammadiyah Gombong terdiri dari beberapa ruangan, diantaranya Ruang Salma, Hidayah, Inayah, Barokah dan Husna. Ruang rawat inap tersebut tersebar pada area dengan kondisi tingkat intensitas suara yang berbeda yang akan menghasilkan sebaran yang berbeda pula. Pengaturan jam besuk, jam istirahat dan jam pemeriksaan dokter akan menimbulkan fluktuasi pada tingkat intensitas suara tersebut. Perlu 
adanya pemantauan secara berkala dan pengendalian agar kondisi intensitas suara di lingkungan tersebut sesuai dengan NAB yang telah ditentukan.

Hasil penelitian Intensitas Suara yang dilakukan oleh Maulydia Septiandari kebisingan di Pabrik Plastik Setia Kawan masih tinggi yaitu diruang percetakan pada shift sore sebesar 85,85 db dan melebihi NAB yang telah ditetapkan oleh Permenakertrans No. 13/Men/X/2011 tentang NAB Faktor Fisika dan Kimia di tempat kerja yaitu $85 \mathrm{db}$.

Perbedaan penelitian ini dengan penelitian sebelumnya adalah untuk mendeskripsikan intensitas suara di ruang rawat inap RS PKU Muhammadiyah Gombong tahun 2017 yang dilakukan di ruang rawat inap RS PKU Muhammadiyah Gombong yang diambil per kelasnya selama 7 waktu pengukuran.

Tujuan dari penelitian ini yaitu untuk mengetahui intensitas suara di ruang rawat inap RS PKU Muhammadiyah Gombong tahun 2017 meliputi pengukuran intensitas suara, mengetahui sumbernya, fluktasi dan sebaran, jenis / sifat bisingnya serta upaya pengendaliannya.

\section{Bahan dan Metode}

Penelitian dilakukan di RS PKU Muhammadiyah Gombong, Jalan Yos Sudarso Nomor 461, Semondo, Gombong, Kebumen, Jawa Tengah 54413 yang dilakukan pada 5 bangsal perawatan dengan masing masing bangsal diambil titik berdasarkan kelasnya dengan parameter yang akan digali adalah tingkat intensitas suara, sebarannya, fluktuasinya, jenis kebisingan, suhu, dan kelembaban.

Penelitian ini dilakukan dengan menggunakan metode observasional dengan analisis deskriptif yang bertujuan untuk mendeskripsikan intensitas suara di ruang rawat inap Rumah Sakit PKU Muhammadiyah Gombong tahun 2017.

\section{Hasil dan pembahasan}

\section{a. Intensitas suara di ruang rawat inap}

Berdasarkan hasil pengukuran intensitas suara di seluruh ruang rawat inap yang menjadi obyek penelitian ,didapatkan mayoritas hasilnya tidak memenuhi syarat berdasarkan standar yang ada pada Keputusan Menteri Kesehatan Republik Indonesia Nomor 1204/ MENKES/ SK/ X/ 2004 tentang Persyaratan Kesehatan Lingkungan Rumah Sakit. Pengukuran dilakukan pada 16 titik yang terdapat pada lima ruangan dan pengukuran dilakukan sebanyak tujuh kali waktu pengukuran. Banyaknya hasil yang tidak memenuhi syarat dikarenakan banyaknya suara - suara yang dihasilkan di lingkungan sekitar ruang rawat inap pada waktu pengukuran, sebagai contoh aktivitas Unit Gizi, perawat, dokter, housekeeper, dan aktivitas renovasi yang sedang berlangsung di lingkungan sekitar ruang rawat inap serta sumber - sumber kebisingan yang lain. Perlu dilakukan pengaturan terhadap tingginya intensitas suara pada ruang perawatan misal dengan memasang tulisan peringatan untuk tidak membuat gaduh pada setiap ruangan , memasang tirai pada jendela untuk menghambat suara yang berasa dari luar ruangan serta pengaturan alat - alat medis serta non-medis agar intensitas suara yang dihasilkan tidak tinggi.

Tabel 1. Hasil pengukuran intensitas suara menurut Kelas di RS PKU Muhammadiyah Gombong tahun 2017

\begin{tabular}{cccc}
\hline No & Kelas & $\begin{array}{c}\text { Rata- rata } \\
\text { Hasil } \\
\text { Pengukuran } \\
\text { (dB) }\end{array}$ & Ruang \\
\hline 1 & Kelas 1 & 57,45 & Hidayah \\
\hline 2 & Kelas 2 & 67,50 & $\begin{array}{c}\text { Husna, } \\
\text { Hidayah }\end{array}$ \\
\hline 3 & Kelas 3 & 52,64 & Husna, Inayah \\
\hline 4 & Kelas & 55,35 & Barokah \\
\hline 5 & Kamkesmas & 49,40 & Husna \\
\hline 6 & Kelas Utama & 50,25 & Salma \\
\hline & Berdasarkan tabel 1. hasil pengukuran intensitas
\end{tabular}

Berdasarkan tabel 1. hasil pengukuran intensitas suara menurut kelas di RS PKU Muhammadiyah Gombong tahun 2017 diperoleh hasil rata - rata intensitas suara terendah yaitu 49,40 dB pada lokasi Kelas Utama dan rata - rata intensitas suara tertinggi yaitu 67,50 dB pada lokasi Kelas 2.

\section{b. Sumber - sumber kebisingan di ruang rawat inap.}

Sumber kebisingan yang ada di RS PKU Muhammadiyah Gombong tahun 2017 didominasi oleh suara aktivitas manusia yang ada di ruang rawat inap, misal pasien, penunggu pasien dan penjenguk pasien maupun suara yang berasal dari luar ruang rawat inap, misal suara perawat di ruang jaga, aktivitas pengunjung di sekitar ruang rawat inap, aktivitas paramedis, unit gizi, buruh bangunan (karena di RS PKU Muhammadiyah Gombong terdapat proses pembangunan), renovasi, aktivitas lalu lintas dan aktivitas housekeeper serta mesin medis dan non medis.

Sumber kebisingan merupakan pusat keluarnya suara yang menganggu dan dapat meningkatkan intensitas suara. Terdapat berbagai macam sumber kebisingan yang ada di ruang rawat inap. Berdasarkan hasil pengamatan sumber kebisingan di seluruh ruang rawat inap yang menjadi obyek penelitian ,didapatkan hasil bahwa sumber kebisingan didominasi oleh suara aktivitas manusia yang ada di ruang rawat inap, misal pasien, penunggu pasien dan penjenguk pasien maupun suara yang berasal dari luar ruang rawat inap, misal suara perawat di ruang jaga, aktivitas pengunjung di sekitar ruang rawat inap, aktivitas paramedis, unit gizi, buruh bangunan (karena di RS PKU Muhammadiyah Gombong terdapat proses pembangunan), renovasi, aktivitas lalu lintas dan aktivitas housekeeper serta mesin medis dan non medis. Banyaknya kegiatan yang 
berkaitan dengan pasien rawat inap menyebabkan intensitas suara yang ada di ruang rawat inap menjadi tinggi, perlu dilakukan pemantauan pada sumber sumber suara yang ada.

\section{c. Sebaran intensitas suara di ruang rawat inap}

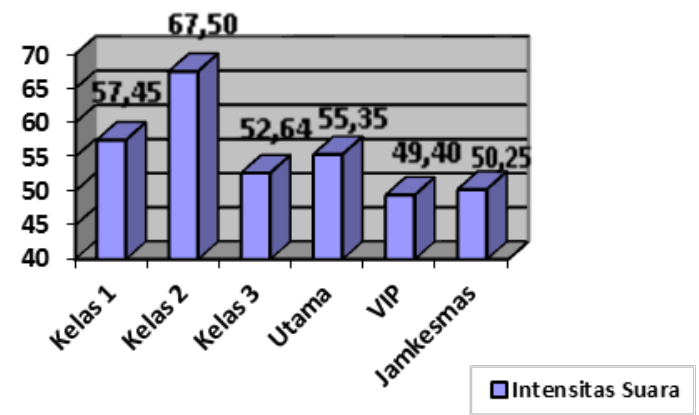

Diagram 1. Sebaran Intensitas Suara di RS PKU Muhammadiyah Gombong tahun 2017 menurut kelas Berdasarkan hasil analisis yang dilakukan dengan menghitung rata -rata hasil pengukuran intensitas suara pada setiap kelasnya didapatkan hasil rata - rata intensitas suara tertinggi berada pada ruang perawatan Kelas 2 (67,50 dB), yang kedua adalah ruang perawatan Kelas 1 (57,45 dB), ketiga ruang perawatan Jamkesmas (55,35 dB), keempat ruang perawatan Kelas 3 (52,64 $\mathrm{dB})$, kelima ruang perawatan VIP (50,25 dB) dan yang keenam adalah ruang perawatan Utama (49,40 dB). Ruang perawatan Kelas 2 mayoritas berada pada Ruang Perawatan Hidayah dimana lokasi ruangannya berhadapan dengan IBS yang mana kursi tunggu pasiennya berada di depan Ruang Hidayah, hal tersebut beresiko meningkatkan intensitas suara di Ruang Perawatan Hidayah. Sedangkan sebagian ruang perawatan Kelas 2 berada pada Ruang Husna yang berlokasi didekat masjid, banyaknya pengunjung rumah sakit yang melakukan aktivitas di masjid menyebabkan intensitas suara yang ada di Ruang Husna meningkat. Berdasarkan hasil pengukuran yang dilakukan perlu adanya pengendalian pada lingkungan sekitar ruang rawat inap salah satunya dengan pemasangan papan peringatan harap tenang serta pengendalian pada ruang rawat inap tersebut dengan melakukan pengendalian pada sumber yang ada di dalam ruang rawat inap.

Ruang perawatan dengan intensitas suara paling rendah yaitu Kelas Utama yang seluruhnya berada pada Raung Husna, dimana dalam satu ruangan kamar hanya terdapat satu bed juga lokasinya berada di lantai dua dan jauh dari pusat keramaian, hal tersebut menghasilkan rendahnya intensitas suara pada ruang tersebut. d. Fluktuasi intensitas suara di ruang rawat inap

1) Fluktuasi intensitas suara pada ruang perawatan Kelas 1

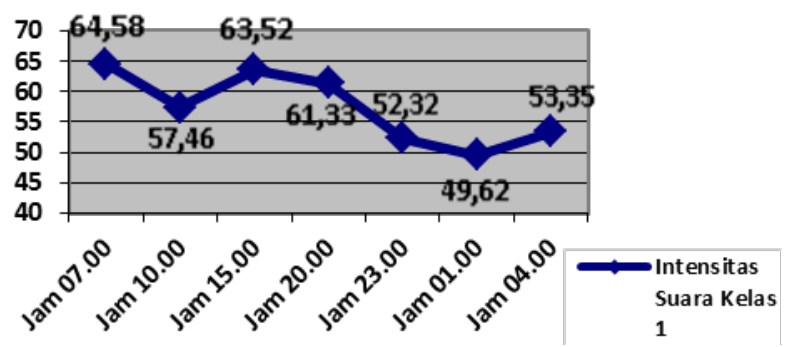

Diagram 2. Fluktuasi Intensitas Suara Kelas 1 di RS PKU Muhammadiyah Gombong tahun 2017

2) Fluktuasi intensitas suara pada ruang perawatan kelas 2

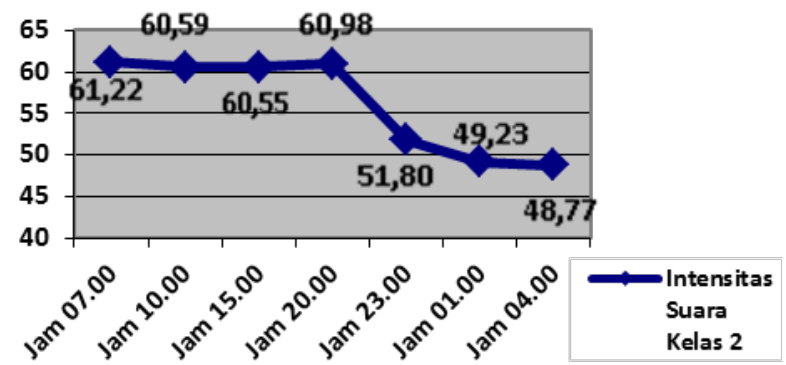

Diagram 3. Fluktuasi Intensitas Suara Kelas 2 di RS PKU Muhammadiyah Gombong tahun 2017

3) Fluktuasi intensitas suara pada ruang perawatan kelas 3

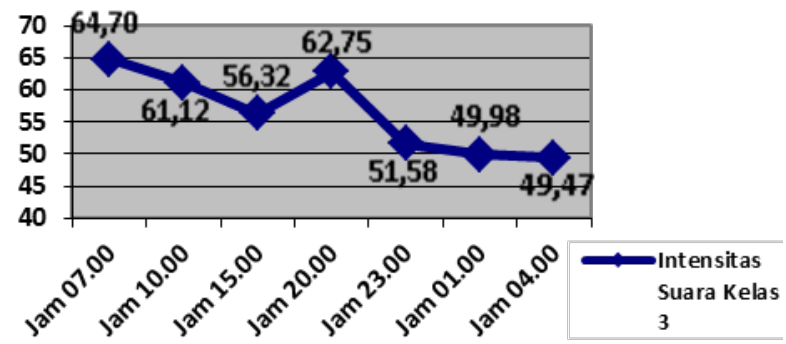

Diagram 4. Fluktuasi Intensitas Suara Kelas 3 di RS PKU Muhammadiyah Gombong tahun 2017

4) Fluktuasi intensitas suara pada ruang perawatan kelas utama

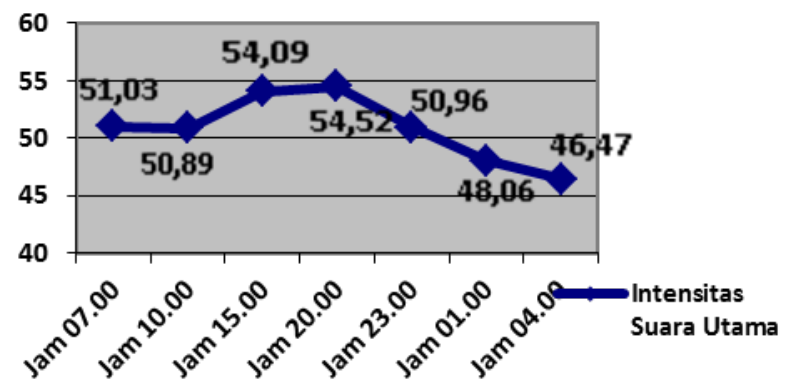


Diagram 5. Fluktuasi Intensitas Suara Kelas Utama di RS PKU Muhammadiyah Gombong tahun 2017

5) Fluktuasi intensitas suara pada ruang perawatan kelas utama

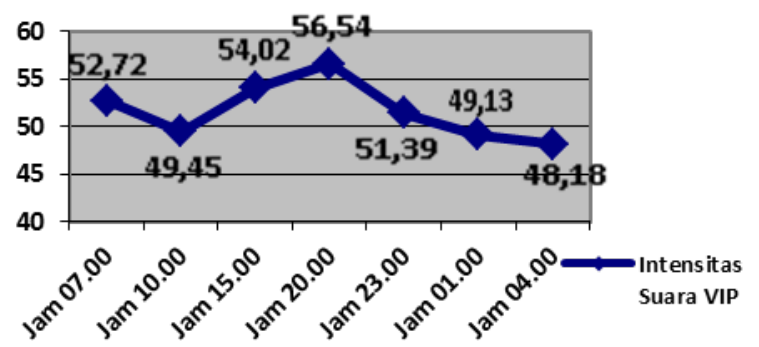

Diagram 6. Fluktuasi Intensitas Suara Kelas VIP di RS PKU Muhammadiyah Gombong tahun 2017

6) Fluktuasi intensitas suara pada ruang perawatan kelas jamkesmas

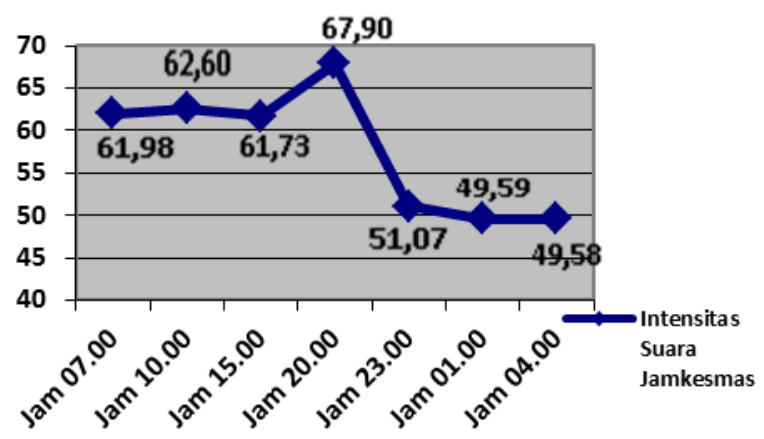

Diagram 7. Fluktuasi Intensitas Suara Kelas Jamkesmas di RS PKU Muhammadiyah Gombong tahun 2017

Berdasarkan hasil analisis yang dilakukan dengan menghitung rata -rata hasil pengukuran intensitas suara pada setiap kelas pada 7 waktu pengukuran didapatkan hasil pada ruang Kelas 1 ,Kelas 2 dan Kelas 3 intensitas suara tertinggi pada jam 07.00 WIB dikarenakan terdapat kegiatan housekeeper pada setiap ruang perawatan. Pada ruang perawatan Utama, VIP dan Jamkesmas intensitas suara tertinggi terjadi pada jam 20.00 WIB dikarenakan waktu tersebut masuk dalam jam kunjungan pasien ,pada Ruang Utama dan VIP yang hanya terdapat satu pasien dalam satu ruangan menyebabkan penjenguk bebas beraktivitas tanpa mementingkan pasien lain. Berdasarkan hal tersebut, perlu dilakukan adanya pengendalian intensitas suara pada sumber - sumber yang ada misal dengan pengaturan jumlah penjenguk dan lamanya waktu menjenguk untuk setiap pasien.

e. Jenis - jenis suara di ruang rawat inap

Berdasarkan hasil pengamatan yang dilakukan selama proses penelitian, didapatkan hasil pengelompokan jenis - jenis suara yang ada di ruang rawat inap. Kategori suara suara menurut Suma'mur (2003,h.167) dan Mukono (2006,h.150) adalah Continu Noise, Intermitten Noise, Impact Noise ,Wide Band Noise, dan Narrow Band Noise. Hasil pengamatan yang dilakukan, jenis Continu Noise yang ditemukan adalah suara kipas angin, penunggu pasien dan penjenguk pasien, aktivitas paramedis dan suara mesin - mesin non medis, jenis Intermitten Noise berupa suara aktivitas lalu lintas, aktivitas housekeeper, aktivitas unit Gizi, aktivitas paramedic, jenis Impact Noise berupa suara aktivitas pertukangan di lingkungan rumah sakit dan aktivitas renovasi, jenis Wide Band Noise berupa suara kegaduhan pasien, suara perawa di ruang jaga, dan aktivitas pengunjung di sekitar ruang rawat inap dan jenis Narrow Band Noise yaitu berupa suara AC dan suara mesin - mesin medis.

4. Kesimpulan

a. Rumah Sakit PKU Muhammadiyah Gombong merupakan rumah sakit swasta yang menyediakan pelayanan raung rawat inap bagi pasien dimana terdapat berbagai aktivitas yang beresiko dapat meningkatkan intensitas suara di ruang rawat inap tersebut sehingga menganggu kenyamanan pasien dalam melakukan pengobatan.

b. Hasil pengukuran suhu yang dilakukan diperoleh suhu terendah yaitu $23^{\circ} \mathrm{C}$ pada lokasi Ruang Husna titik 1 dan 2 jam pengukuran 07.00 WIB Ruang Salma titik 2 jam pengukuran $04.00 \mathrm{WIB}$, suhu tertinggi yaitu $29{ }^{\circ} \mathrm{C}$ pada lokasi Ruang Inayah titik 1 jam pengukuran 20.00 WIB dan titik 2 jam pengukuran 07.00 WIB.

c. Hasil pengukuran kelembaban yang dilakukan diperoleh kelembaban terendah yaitu $34 \%$ pada lokasi Ruang Inayah titik 1 jam pengukuran 10.00 WIB dan kelembaban tertinggi yaitu $57 \%$ pada lokasi Ruang Hidayah titik 2 jam pengukuran 04.00 WIB.

d. Hasil pengukuran intensitas suara yang dilakukan diperoleh hasil intensitas suara terendah yaitu 42,69 dB pada lokasi Ruang Salma titik 3 jam pengukuran 10.00 WIB dan intensitas suara tertinggi yaitu 76,25 dB pada lokasi Ruang Husna titik 4 jam pengukuran 07.00 WIB. e. Sumber - sumber kebisingan di ruang rawat inap berdasarkan hasil pengamatan didominasi oleh suara aktivitas manusia yang ada di ruang rawat inap, misal pasien, penunggu pasien dan penjenguk pasien maupun suara yang berasal dari luar ruang rawat inap, misal suara perawat di ruang jaga, aktivitas pengunjung di sekitar ruang rawat inap, aktivitas paramedis, unit gizi, buruh bangunan (karena di RS PKU Muhammadiyah Gombong terdapat proses pembangunan), renovasi, aktivitas lalu lintas dan aktivitas housekeeper serta mesin medis dan non medis.

f. Sebaran intensitas suara yang dihitung berdasarkan rata - rata hasil pengukuran pada setiap kelas di ruang perawatan didapatkan hasil sebaran tertinggi terdapat pada Kelas 2 (67,50 dB) , Kelas 1 (57,45 dB), Jamkesmas (55,35 dB), Kelas (52,64 dB), Kelas VIP (50,25 dB) dan Kelas Utama (49,40 dB).

g. Fluktuasi intensitas suara yang dihitung berdasarkan rata - rata hasil pengukuran pada setiap kelas ruang perawatan dalam 7 waktu pengukuran didapatkan hasil 
pada Ruang Kelas 1 fluktuasi tertinggi pada jam pengukuran 07.00 WIB $(64,58 \mathrm{~dB})$, Kelas 2 tertinggi pada jam pengukuran 07.00 WIB (61,22 dB), Kelas 3 tertinggi pada jam pengukuran 07.00 WIB $(64,70 \mathrm{~dB})$, Kelas Utama tertinggi pada jam pengukuran 20.00 WIB (54,52 dB), Kelas VIP tertinggi pada jam pengukuran 20.00 WIB (56,54 dB) dan Kelas Jamkesmas tertinggi pada jam pengukuran 20.00 WIB (67,90 dB).

h. Jenis - jenis suara yang ditemukan berdasarkanhasil pengamatan di ruang rawat inap antara lain continu noise (kipas angin, penunggu pasien dan penjenguk pasien, aktivitas paramedis dan suara mesin - mesin non medis, Intermitten noise (Aktivitas lalu lintas, aktivitas housekeeper, aktivitas unit Gizi, aktivitas paramedis), impact noise (aktivitas pertukangan di lingkungan rumah sakit dan aktivitas renovasi), wide band noise (suara kegaduhan pasien, suara perawat di ruang jaga, dan aktivitas pengunjung di sekitar ruang rawat inap) dan narrow band noise (suara AC dan suara mesin mesin medis)

\section{Daftar Pustaka}

A.Aziz Hidayat,2007,Metode Penelitian Kebidanan dan Teknis Analisis Data,Jakarta:Salemba Medika

Babba,Jennie,2007, Hubungan antara Intensitas Kebisingan di Lingkungan Kerja dengan Peningkatan Tekanan Darah, Penelitian, Sulawesi Selatan

Budiman Chandra,2007,Pengantar Kesehatan Lingkungan,Jakarta: Penerbit Buku Kedokteran EGC

Dedy Tri Yuliando,2012, Kebisingan,Padang: https://tryyyyuliando.files.wordpress.com/2 012/07/jurnal-bising-dedy-try-yuliando.doc diakses pada tanggal 31 Januari jam 8.47 WIB

Departemen Kesehatan RI,2001,Pedoman Teknis Upaya Kesehatan Kerja Di Rumah Sakit,Jakarta:Depkes RI

Ekasanti Widhiaputri,2013,Studi tentang Intensitas Suara dan Upaya Pengendaliannya pada Ruang Turbin PT. Indonesia Power UBP Mrica Banjarnegara tahun 2013, KTI, Purwokerto: Kementerian Kesehatan RI Politeknik Kesehatan Semarang Jurusan Kesehatan Lingkungan Purwokerto

http://www.mipa-farmasi.com/2016/09/definisi-danklasifikasi-rumah-sakit.html diakses pada tanggal tanggal 26 Januari 2017 jam 22.28 WIB

__://www.scribd.com/doc/100733528/Cara-

Pengendalian-Kebisingan diakses pada tanggal 26 januari 2017 jam 23.28 WIB
://www.tenmars.com/webls-en-us/TM-102.html diakses pada tanggal 17 Januari 2017 jam 10.43 WIB

H.J Mukono,2006,Prinsip Dasar Kesehatan Lingkungan,Surabaya:Penerbit Buku Percetakan Unair

Lembar Kerja Praktikum Keselamatan dan Kesehatan Kerja,2016, Purwokerto:Jurusan Kesehatan Lingkungan Puwokerto

Maulydia Septiandari,2012,Studi Intensitas Suara Pada Bagian Produksi Pabrik Plastik Setia Kawan Purwokerto Tahun 2012, KTI, Purwokerto: Kementerian Kesehatan RI Politeknik Kesehatan Semarang Jurusan Kesehatan Lingkungan Purwokerto

Pusat Pembinaan dan Pengembangan Bahasa,1995,Kamus Besar Bahasa Indonesia,Jakarta:Balai Pustaka

PKU Muhammadiyah Gombong,2016, laporan pengukuran cuaca kerja RS PKU Muhammadiyah Gombong,Gombong:IPL RS PKU Muhammadiyah Gombong ,2017, struktur organisasi RS PKU Muhammadiyah Gombong,Gombong:IPL RS PKU Muhammadiyah Gombong ,2017, laporan pengelolaan lingkungan RS PKU Muhammadiyah Gombong, Gombong: IPL RS PKU Muhammadiyah Gombong

Republik Indonesia,1996,Keputusan Menteri Negara Lingkungan Hidup Nomor:Kep-48/ MENLH/ 11/ 1996 tentang Baku Tingkat Kebisingan,Jakarta:KemenLH RI ,2002, Keputusan Menteri Kesehatan RI No. 1405 Tahun 2002 tentang Persyaratan Kesehatan Lingkungan Kerja Perkantoran dan Industri,Jakarta: Kemenkes RI ,2004,Keputusan Menteri Kesehatan RI Nomor 1204/MENKES/SK/X/2004 tentang persyaratan kesehatan lingkungan Rumah Sakit,Jakarta: Kemenkes RI 2009, Undang-Undang Republik Indonesia Nomor 36 Tahun 2009 Tentang Kesehatan, Jakarta : Kepmenkes RI. ,2009, Undang-undang Nomor 44 tahun 2009 tentang Rumah Sakit,Jakarta:http://www.depkes.go.id/resou rces/download/peraturan/UU\%20No.\%2044 \%20Th\%202009\%20ttg\%20Rumah\%20Sak it.PDF diakses pada tanggal 17 Januari 2017 jam 12.11WIB ,2011,Kementerian Tenaga Kerja Dan Transmigrasi, Permenakertrans no. 13/MEN/X/2011 Tentang Nilai Ambang 
Batas Faktor Fisika Dan Faktor Kimia Di Tempat Kerja,Jakarta:Kemenakertrans RI ,2014, Permenkes Nomor 56 tahun 2014 tentang Klasifikasi dan Perizinan Rumah sakit,Jakarta:Kemenkes RI 2016, Kementrian Kesehatan, Permenkes Nomor 24 tahun 2016 Tentang Persyaratan Teknis Bangunan dan Prasarana Rumah Sakit,Jakarta: Kemenkes RI

Selvina Levina Ukru,2016,Kebisingan Di Rumah Sakit Siloam Manado Sebagai Fungsi Jumlah Kendaraan Yang Melewati Jalan Sam Ratulangi Manado,Manado: http://ejournal.unsrat.ac.id/index.php/jmuo diakses pada tanggal 31 Desember 2016 jam 14.17

Soeripto M,2008, Higiene Industri,Jakarta: Fakultas kedokteran UI

Suma'mur PK,2013, Higiene Perusahaan Dan Kesehatan Kerja (Hiperkes), Jakarta, Universitas Indonesia

Tarwaka,Solichul,Lilik Sudiajeng,2008,Ergonomi untuk Kesehatan, Keselamatan Kerja dan Prosuktivitas,Surakarta:UNIBA Press

Tri Widi Astuti,2012, Studi tentang Intensitas Suara dan Upaya Pengendalian Kebisingan Bagian Utilities 50 PT. Pertamina (Persero) Refinery Unit IV Cilacap Tahun 2012,KTI, Purwokerto: Kementerian Kesehatan RI Politeknik Kesehatan Semarang Jurusan Kesehatan Lingkungan Purwokerto

WHO (World Health Organization),2010,Kebisingan Di Tempat Kerja, Jakarta:Universitas Indonesia 